\section{Commentary: Much ado about nothing: Resect or respect?}

\author{
Patrick M. McCarthy, MD
}

Chevy or Ford? Lite Beer or regular? Brady or Mahomes? We are faced with choices that some people feel are clearcut, and they are passionate about their opinions. But many times, under close scrutiny of the data, these are revealed as strong opinions without much supporting data. We have our share of false debates in cardiac surgery as well. I get drawn into the sternotomy versus robotics/right thoracotomy, full biatrial Maze versus left atrial only lesion set, and, more recently, the "respect" (neochords) versus resect mitral repair debates. Some criticize my approach for mitral operations because I make a midline incision to maximize patient safety, and I note in debates that all our operations are on cardiopulmonary bypass with the heart stopped, no matter where the incision is made. The only real revolution is in transcatheter mitral techniques. Some purists think all surgical atrial fibrillation (AF) ablation needs to be a biatrial Maze in nearly all patients, but that opinion is based largely on data from patients with $\mathrm{AF}$ alone and has little relevance for patients with severe mitral regurgitation (MR) or stenosis. MR patients referred early have normal pulmonary artery pressures, no right ventricular/ right atrial enlargement, mild or less tricuspid regurgitation, recent paroxysmal AF, and few AF symptoms. A focused left atrial lesion set with a left atrial appendage clip shortens cardiopulmonary bypass time and perhaps decreases pacemaker use and potential right atriotomy bleeding. ${ }^{1}$

From the Division of Cardiac Surgery, Department of Surgery, Bluhm Cardiovascular Institute, Northwestern University Feinberg School of Medicine and Northwestern Medicine, Chicago, Ill.

Disclosures: The author reports receiving royalties and speaking fees from Edwards Lifesciences and speaking fees from Atricure and Medtronics.

The Journal policy requires editors and reviewers to disclose conflicts of interest and to decline handling or reviewing manuscripts for which they may have a conflict of interest. The editors and reviewers of this article have no conflicts of interest.

Received for publication Feb 15, 2021; revisions received Feb 15, 2021; accepted for publication Feb 17, 2021; available ahead of print Feb 22, 2021

Address for reprints: Patrick M. McCarthy, MD, Division of Cardiac Surgery, Northwestern University, Northwestern Memorial Hospital, 201 East Huron St, Suite 11140, Chicago, IL 60611-2968 (E-mail: pmccart@nmh.org).

J Thorac Cardiovasc Surg 2022;164:1498-9

$0022-5223 / \$ 36.00$

Copyright $\subset 2021$ by The American Association for Thoracic Surgery

https://doi.org/10.1016/j.jtcvs.2021.02.056

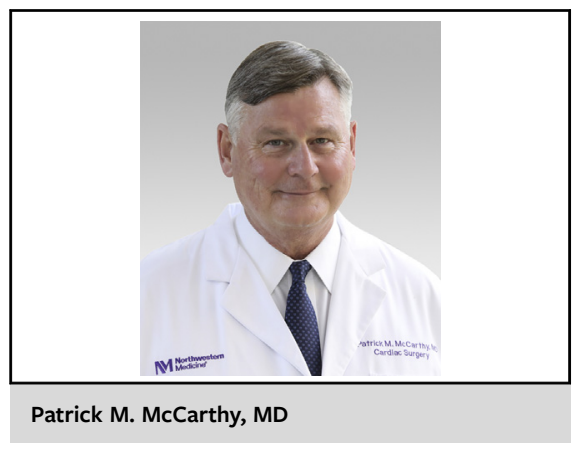

CENTRAL MESSAGE

The debate regarding the supe-

riority of leaflet resection versus

neochords for degenerative

mitral repair should end; both

work well, and the surgeon can

safely apply either.

In their article in this issue of the Journal, van Wijngaarden and colleagues ${ }^{2}$ report that leaflet resection and chordal replacement were equally effective at preserving postoperative left ventricular function in their study cohort. $^{2}$ Twenty-year results from Tirone David show great durability with the frequent use of neochords in his series. ${ }^{3}$ Alfieri and colleagues ${ }^{4}$ reported 19-year data with a resection technique that show nearly identical results to Dr David's. Using only resection with a quantitative, measured approach, we found a 10-year freedom from reoperation of $99.8 \%$ and freedom from more than moderate MR of $98.6 \% .^{5}$ Randomized trials of neochords versus resection techniques show clinical equivalence. $^{6}$

I do not use neochords because they require judgment and a little "art" in surgery, but I admit that is my opinion. Sometimes when I do a reoperation for failed neochord repair, the valve looks like a Picasso portrait-not a good look for a mitral valve. ${ }^{7}$ I am a surgeon, definitely not an artist, and so have no qualms about using a "paint by numbers" approach with my resection technique. We have plenty of important debates in our field, such as surgical versus transcatheter aortic valve replacement for low-risk young patients, transcatheter treatment versus surgery for some degenerative MR patients, and coronary artery bypass versus percutaneous coronary intervention for left main disease. It is time we moved on from our old debates and accept the obvious: some things are 
equivalent even though different. Do what works best in your hands.

\section{References}

1. Churyla A, Iddriss A, Andrei AC, Kruse J, Malaisrie SC, Passman R, et al. Biatrial or left atrial lesion set for ablation during mitral surgery: risks and benefits. Ann Thorac Surg. 2017;103:1858-65.

2. van Wijngaarden AL, Tomšič A, Mertens BJA, Fortuni F, Delgado V, Bax JJ, et al. Mitral valve repair for isolated posterior mitral valve leaflet prolapse: the effect of respect and resect techniques on left ventricular function. J Thorac Cardiovasc Surg. 2022;164:1488-97.e3.

3. David TE, David CM, Tsang W, Lafreniere-Roula M, Manlhiot C. Long-term results of mitral valve repair for regurgitation due to leaflet prolapse. J Am Coll Cardiol. 2019;74:1044-53
4. Lapenna E, Del Forno B, Amore L, Ruggeri S, Iaci G, Schiavi D, et al. Durability at 19 years of quadrangular resection with annular plication for mitral regurgitation. Ann Thorac Surg. 2018;106:735-41.

5. McCarthy PM, Herborn J, Kruse J, Liu M, Andrei AC, Thomas JD. A multiparameter algorithm to guide repair of degenerative mitral regurgitation. J Thorac Cardiovasc Surg. October 10, 2020 [Epub ahead of print].

6. Chan V, Mazer CD, Ali FM, Quan A, Ruel M, de Varennes BE, et al. Randomized, controlled trial comparing mitral valve repair with leaflet resection versus leaflet preservation on functional mitral stenosis: the CAMRA CardioLink-2 study. Circulation. 2020;142:1342-50.

7. Antunes MJ. Commentary: repair of degenerative mitral regurgitation: science, art, or both? J Thorac Cardiovasc Surg. 2020 [In press].

8. Gillinov AM, Burns DJP, Wierup PN. Commentary: mitral valve repair: voodoo, art, and science. J Thorac Cardiovasc Surg. October 17, 2020 [Epub ahead of print].
See Article page 1488.

\section{Commentary: Left ventricular function after mitral valve repair}

\author{
Tirone E. David, MD
}

This retrospective study by van Wijngaarden and colleagues ${ }^{1}$ from Leiden University on postoperative left ventricular function following mitral valve repair for posterior leaflet prolapse treated either by resection or chordal replacement shows that the technique used to correct the leaflet prolapse had no effect on postoperative left ventricular function. The study is retrospective and has several other limitations, as noted by the authors. However, even if they had randomized their patients and stratified by variables known to affect postoperative ventricular function, the results would have been the same.

I have performed mitral valve repair in more than 3000 patients, and my research assistants have followed them postoperatively with periodical echocardiography to assess both valve and ventricular function. Postoperative ventricular dysfunction after the correction of chronic mitral regurgitation is a complex, frustrating, and incompletely defined

\footnotetext{
From the Division of Cardiovascular Surgery, Peter Munk Cardiac Centre at Toronto General Hospital and University of Toronto, Toronto, Ontario, Canada. Disclosures: The author reported no conflicts of interest.

The Journal policy requires editors and reviewers to disclose conflicts of interest and to decline handling or reviewing manuscripts for which they may have a conflict of interest. The editors and reviewers of this article have no conflicts of interest.

Received for publication Feb 16, 2021; revisions received Feb 16, 2021; accepted for publication Feb 17, 2021; available ahead of print Feb 22, 2021.

Address for reprints: Tirone E. David, MD, Division of Cardiovascular Surgery, Peter Munk Cardiac Centre, 200 Elizabeth St, 4N453, Toronto, Ontario M5G 2C4, Canada (E-mail: tirone.david@uhn.ca).

J Thorac Cardiovasc Surg 2022;164:1499-500

$0022-5223 / \$ 36.00$

Copyright (c) 2021 by The American Association for Thoracic Surgery

https://doi.org/10.1016/j.jtcvs.2021.02.052
}

Check for updates

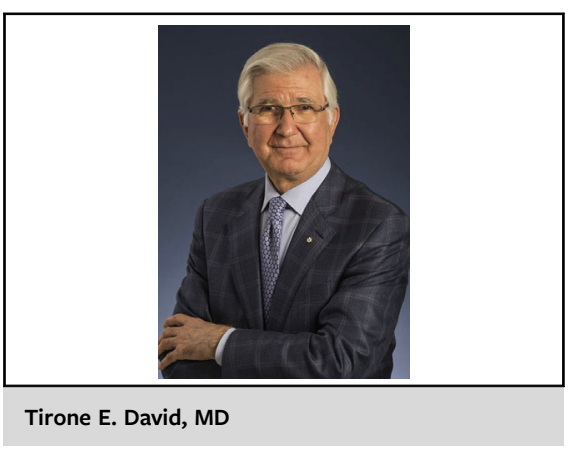

CENTRAL MESSAGE

The surgical technique used for correction of chronic mitral regurgitation due to leaflet prolapse has no effect on postoperative left ventricular function.

problem. Patients with apparently normal systolic function before surgery sometimes develop severe ventricular dysfunction that impairs their functional capacity and late survival. ${ }^{2}$ As long as the heart is well protected during surgery and the circumflex artery is not kinked or ligated, what we do mechanically to correct the regurgitant lesion has no known effect on ventricular function. The type of annuloplasty ring also has no effect on ventricular function ${ }^{2}$; ditto for the type of correction of leaflet prolapse.

I do not believe that chordal replacement is superior to resection in treating posterior leaflet prolapse and have used both techniques depending on the size, height, and 